This is an electronic reprint of the original article. This reprint may differ from the original in pagination and typographic detail.

Author(s): Lyytinen, Heikki; Erskine, Jane; Tolvanen, Asko; Torppa, Minna; Poikkeus, Anna-Maija; Lyytinen, Paula

Title: $\quad$ Trajectories of reading development: A follow-up from birth to school age of children with and without risk for dyslexia

Year: $\quad 2006$

Version:

Please cite the original version:

Lyytinen, H., Erskine, J., Tolvanen, A., Torppa, M., Poikkeus, A.-M., \& Lyytinen, P. (2006). Trajectories of reading development: A follow-up from birth to school age of children with and without risk for dyslexia. Merrill-Palmer Quarterly, 52(3), 514-546. https://doi.org/10.1353/mpq.2006.0031

All material supplied via JYX is protected by copyright and other intellectual property rights, and duplication or sale of all or part of any of the repository collections is not permitted, except that material may be duplicated by you for your research use or educational purposes in electronic or print form. You must obtain permission for any other use. Electronic or print copies may not be offered, whether for sale or otherwise to anyone who is not an authorised user. 


\section{Trajectories of Reading Development: A Follow-up From Birth to School Age of Children With and Without Risk for Dyslexia}

Heikki Lyytinen, Jane Erskine, Asko Tolvanen, Minna Torppa, Anna-Maija Poikkeus, and Paula Lyytinen, University of Jyväskylä, Finland

In order to understand why some children are vulnerable to difficulties in their language development and their acquisition of reading skill, the Jyväskylä Longitudinal Study of Dyslexia followed 200 Finnish children from birth to school age. Half of these children had a family history of reading problems and were considered at risk for dyslexia; the other half were not at risk. A novel analysis, mixture modeling, revealed four subgroups with differential developmental trajectories to early reading. The subgroups who showed either a "dysfluent trajectory" ( $n=12 ; 11$ at risk vs. 1 control) or a "declining trajectory" ( $n=35 ; 24$ vs. 11) contained more children with familial risk for dyslexia. The subgroup showing an "unexpected trajectory" contained equal numbers of at-risk and non-risk children ( $n=67 ; 33$ vs. 34$)$. The subgroup displaying a "typical trajectory" ( $n=$ 85,38 vs. 47) contained more children born without dyslexia risk. This differential development of skills revealed that there are at least three troubled routes along which a child may ultimately encounter difficulties in reading acquisition. The most explicit routes are characterized by problems in either phonological awareness, naming speed, or letter knowledge-problems that increase in severity with age.

Heikki Lyytinen, Jane Erskine, Asko Tolvanen, Minna Torppa, Anna-Maija Poikkeus, and Paula Lyytinen, Department of Psychology and Child Research Center.

The Jyväskylä Longitudinal Study of Dyslexia (JLD) belongs to the Finnish Center of Excellence Program (2000-2005) and has been supported by the Academy of Finland, Niilo Mäki Institute, and University of Jyväskylä. We would like to thank the families in the study. Thanks also to the reviewers and editors of this journal for their valuable comments on earlier versions of the text.

Correspondence concerning this article should be directed to Heikki Lyytinen, University of Jyväskylä, PO Box 35; Fin-40014, University of Jyväskylä, Finland. E-mail: Heikki.Lyytinen @ psyka.jyu.fi.

Merrill-Palmer Quarterly, July 2006, Vol. 52, No. 3, pp. 514-546. Copyright (C) 2006 by Wayne State University Press, Detroit, MI 48201. 
One of the best ways to understand developmental disorders is through a prospective follow-up study, especially if it is initiated before the environment can exert its effect on the emerging developmental routes. The Jyväskylä Longitudinal Study of Dyslexia (JLD) is one such prospective follow-up from birth to school age of 200 Finnish children, half of whom were at familial risk for dyslexia. Over a period of 9 years, the children underwent a plethora of assessments drawing on all psychological disciplines. These included measures assessing early auditory cognition (with event-related potentials, or ERPs), early language (expressive and receptive), cognitive abilities, and recognized correlates to literacy, including phonological awareness, naming speed, letter naming, and early decoding skills. Typically, Finnish children attend preschool or kindergarten at age 6, with formal schooling and reading instruction beginning at age 7 when they enter first grade. The youngest of the JLD children were about to enter third grade, so we had access to data covering birth to second grade. We drew on these data to identify factors in the development of the children's language skills that predict the children's ease in reading acquisition and their problems in foundation-level reading.

We now know that dyslexia is affected by genes, and recently it has been connected even to a single gene (Taipale et al., 2003). It is also clear from the earlier literature (Scarborough, 1990; Snowling, Gallagher, \& Frith, 2003) that two domains are integral to dyslexia: the general language domain, including speech and language development, and the more literacyspecific language domain, including the phonological domain. We believe they should be considered separately to ascertain the extent to which they are distinct with regard to reading. During the first years of life, isolating different courses in terms of language development is complex. Nonetheless, even relatively undifferentiated indices of the development of early language, such as measures of early speech comprehension and production, create a basis for the prediction of language skills that emerge later.

During their exposure to spoken language, children's evolutionarily more universal sensitivity to sounds becomes redundant as they learn to home in on those aspects of language that discriminate meaning within their particular language environment (Kuhl, Williams, Lacerda, Stevens, \& Lindblom, 1992). Such results show how interest in and implicit attention to aspects of sounds drills the brain's sensitivity to those aspects in a vein similar to how Gibson (1970) describes the development of perception in general.

Elsewhere (for a review of results, see H. Lyytinen, Leppänen, Richardson, \& Guttorm, 2003) we have reviewed our data connecting speech sound processing in the brain and accuracy of speech perception to familial risk for dyslexia. The brains of the JLD at-risk infants differed 
from controls at birth in terms of the processing of speech sounds (Guttorm, Leppänen, Richardson, \& Lyytinen, 2001; Guttorm, Leppänen, Tolvanen, $\&$ Lyytinen, 2003). In addition, preparedness to develop accuracy in the sensitivity to semantically distinctive features (i.e., categorical perception) also varied between the JLD infants with and without risk, as reflected in brain-event-related potential recordings (Leppänen, Eklund, \& Lyytinen, 1997) and in behavioral measurements using a head-turn paradigm (Richardson, 1998). Importantly, and as one of the catalysts to the current pursuit, these speech-processing differences documented immediately after birth and the brain and behavioral indices collected at the age of 6 months were also found to correlate to later language development and to reading acquisition (Guttorm et al., 2005; for a review of the latest psychophysiological findings from the JLD see H. Lyytinen, Guttorm, et al., 2005).

The most prominent subdomain of language development relative to routes to reading acquisition is the phonological domain (Vellutino, Fletcher, Snowling, \& Scanlon, 2004). Studies of at-risk children have shown deficits in phonological awareness (Scarborough, 1990), and regression techniques have revealed that the phonological processing abilities of kindergartners and preschoolers can predict later reading ability and, ultimately, reading disability (Lundberg, 1994; Wagner, Torgesen, \& Laughon, 1993). Intervention studies with at-risk children have also shown that phonologically based reading intervention is critical to skilled reading (Shaywitz et al., 2004).

Our early predictive signs based on speech processing and differentiating children with and without familial risk for reading difficulties reveal an atypicality that compromises phonological accuracy and possibly affects language development in general (Guttorm et al., 2005; see also H. Lyytinen, Guttorm, et al., 2005, for review and the most recent evidence). Perceptual problems may delay the acquisition of explicit phonemic awareness required for reading (see, e.g., Goswami \& Bryant, 1990, for a review). At the same time, insensitivity reflected in speech processing may also affect language development in a more general way. For instance, it is assumed that optimal vocabulary growth is facilitated by the combination of a rich linguistic environment (diversity of input) and intact abilities for continuous phonological restructuring of the representations forming one's vocabulary (e.g. Fowler, 1991; Hoff \& Naigles, 2002; Metsälä \& Walley, 1998).

Research demonstrating the existence of multiple, autonomous routes to compromised reading acquisition is relatively sparse. Unitary claims (Snowling, 1998; Stanovich, 1990), for the most part, have focused on "core" features such as a phonological deficit as underlying reading problems, while previous attempts to differentiate the characteristic error pat- 
terns of dyslexia into distinct phonological (Beauvois \& Derouesné, 1979) or surface (Coltheart, Masterson, Byng, Prior, \& Riddoch, 1983; Marshall $\&$ Newcombe, 1973) subtypes have eluded replication. Moreover, in consistent languages such as Finnish, ${ }^{1}$ surface-type errors are redundant in the language. In consistent orthographies with low levels of ambiguity in the relationship between letters and sounds, the focus leans toward dysfluent reading (Wimmer, 1993) as the primary characteristic, with a more secondary emphasis placed on errors. The degree of individual variation and overlap with regard to the deficits displayed by dyslexic individuals has made the categorical separation of distinct patterns difficult (Leinonen et al., 2001; see Erskine \& Seymour, 2005, for their Cognitive Mosaic Model). Alongside this individual variation, the preparatory skills for a multifactorial ability such as reading are unlikely to vary dichotomously but continuously. It seems apparent, therefore, that different constellations of specific weaknesses form critical "drops" in the skill profiles that may compromise reading acquisition and/or the automatization of reading skill and that such characteristics may form differentiable developmental profiles that we are able to detect using the present methodology.

\section{Rationale for Selection of Critical Developmental Skill Domains}

A comprehensive developmental data set spanning 6 years was used for the modeling. Although we acknowledge that basic processes, such as speech perception, create the foundation for the later phonological development (e.g., Bradley \& Bryant, 1983), in the present context we restricted our analysis to the use of our early behavioral measures. Seven skill domains were produced from these early measures, including (1) receptive and (2) expressive language skills, (3) inflectional morphology skills (general language domain), (4) memory, (5) retrieving words efficiently from memory (naming speed), (6) letter knowledge, and (7) phonological awareness skills. The development of knowledge relating to visual language (e.g., letter knowledge) is an integral part of the foundation skills necessary for reading acquisition and thus constitutes a necessary component of the analyses.

It is well documented that language begins to differ between children with and without risk for dyslexia prior to 3 years of age (Locke et al., 1997) and not only continues to do so but also correlates to later reading

1. Finnish is a highly orthographically consistent language whereby almost all graphemes (in this case, single letters) match consistently with a single phoneme and vice versa. This stands in marked contrast to more inconsistent languages such as English, where the connections between grapheme and phoneme can entail a one-on-many and many-on-one relationship. 
beyond this age (H. Lyytinen, Aro, Eklund, et al., 2004; Scarborough, 1990). The earliest significant predictive correlations from our data are from age 2 years onward (H. Lyytinen, Aro, Holopainen, et al., 2006). For the present modeling we used composite scores of both receptive and expressive language from ages 1 to 5.5 years, capitalizing on parental ratings of early language (MacArthur Communicative Development Inventory, CDI; Fenson et al., 1994) and well-known tests (e.g., Reynell Developmental Language Scales, Reynell \& Huntley, 1987; Peabody Picture Vocabulary Test-R, Dunn \& Dunn, 1981; Boston Naming Test, Kaplan, Goodglass, \& Weintraub, 1983).

Our third developmental domain comprised inflectional morphology. The Finnish language contains fusional agglutinative morphology with very rich and complex sequential inflections and frequent stem variations. A single word can have hundreds or even thousands of variants (Karlsson, 1999). Many of these variations are differentiated by single phonemes (e.g., kodissa [at home]; kodista [from home]). Thus, a child who is able to inflect Finnish accurately must have a proficient implicit ability to manipulate small phonological units. This makes morphological skills highly interesting in our present modeling, as these skills must be mastered (and are easily available for assessment) before the higher-level phonological awareness skills can emerge (i.e., explicit manipulation of phoneme level units). In contrast to English, morphological awareness plays no explicit role in the pronunciation of the Finnish written language. The Finnish writing system is entirely phonological. Every word can be read accurately through knowledge of the letter-sounds and by assembling these in a row as dictated by letters in the written word. However, the morphology affects the average length of Finnish words, which are much longer than in most nonagglutinative languages such as English. Furthermore, as fluency of reading (necessary for reading continuous text due to working memory limits) is the aspect of reading that is most often compromised among Finnish individuals with dyslexia (see, e.g., Holopainen, Ahonen, \& Lyytinen, 2001), morphology, albeit indirectly, is likely to affect reading. That morphological skills are associated with reading development in Finnish is also documented by data from the JLD (H. Lyytinen, Aro, Holopainen, et al., 2006).

We included verbal short-term memory as the fourth developmental skill domain in our modeling. It has been awarded a central role in reading research, possibly because of contentions concerning its overlap with phonological skills (e.g., Pennington, 1991), that is, the requirement of the phonological loop to maintain pronounceable material in memory for short durations. Phonological memory is required for the development of letter knowledge (DeJong \& Olson, 2004), which, in turn, is highly predictive of 
reading acquisition (e.g., Wagner, Torgesen, \& Rashotte, 1994; observed also in the JLD, see H. Lyytinen, Aro, Holopainen, et al., 2006; H. Lyytinen, Ronimus, Alanko, Taanila, \& Poikkeus, submitted). In addition, Gathercole and Baddeley (1997) have argued that phonological memory mediates long-term learning as representations of new phonological forms provide a basis for more permanent representations of new vocabulary.

Our fifth skill domain, retrieval of speech sounds as a continuous sequence as assessed by rapid serial naming, shares central cognitive components with reading (Wolf, 1984). Many identify naming speed as a subdomain of phonological skills (e.g. Vellutino et al., 2004), while others consider the processes measured by rapid serial naming (assessed using RAN, Rapid Automatized Naming Test, by Denckla \& Rudel, 1976) tasks to be independent of phonological processing (Manis, Seidenberg, \& Doi, 1999; Wolf \& Bowers, 1999).

Especially in consistent orthographies, high predictive associations have been observed between reading and serial naming speed (Holopainen et al., 2001; Korhonen, 1995; Wimmer, Mayringer, \& Landerl, 1998). Because gains through intervention appear to be more difficult to achieve in terms of the fluency reflected in naming speed and reading rate rather than in accuracy of phonological skills (DeJong \& Vrielink, 2004; Thaler, Ebner, Wimmer, \& Landerl, 2004), early detection of difficulties in fluency is all the more important.

Letter knowledge is known to be one of the most important early correlates of reading acquisition (e.g., Adams, 1990; Byrne, 1998; Elbro, Borstrøm, \& Petersen, 1998; Gallagher, Frith, \& Snowling, 2000; Lonigan, Burgess, \& Anthony, 2000; H. Lyytinen et al., submitted; Pennington \& Lefly, 2001; Scarborough, 2001; Snow, Burns, \& Griffin, 1998). Thus, our sixth developmental skill domain comprised the yearly assessments of the children's letter knowledge. Letter names direct a child's attention toward phonemes and contribute critically to the development of phonemic awareness.

In the highly literate Finnish culture, practically all children learn some letters long before entering school. At the time of data collection for the present study, the practice in Finnish kindergartens has been to start introducing letters 1 year before formal schooling. Consequently, the spontaneous acquisition of foundation-level decoding skills has increased to about one third of those entering the first-grade population. Interestingly, our groups of children with and without risk differ from each other in their letter knowledge at all ages of assessments, even though the participating families have been amply exposed to the idea that a rich home literacy environment and early shared reading is one of the best ways to afford the children maximum support in their orientation to written language, and parents 
in the two groups do not show differences in the degree to which they have followed these guidelines in their homes (Torppa et al., submitted).

The complex interplay between children's literacy environment and their differential liability to environmental effects at different ages is interestingly visible in our data. Laakso, Poikkeus, Eklund, and Lyytinen (2004) showed that, at 14 months of age, infant shared reading interest (reflected in their observed ability to sustain interest in shared reading with their parent) predicted global language skills and letter knowledge at 3.5 years of age only among children in the control group. On the other hand, Torppa et al. (submitted) found recently that, at later ages, the amount of shared reading predicted vocabulary in both groups but that children's interest in literacy versus other activities (as reported by parents at 4, 5, and 6 years of age) is positively associated with the growth of their phonological awareness skills, but only among children in the at-risk group. Furthermore, Torppa et al.'s analyses showed that vocabulary predicted children's reading interest in the at-risk group only. We feel that this at first seemingly contradictory result suggests that one needs to pay careful attention to person and context factors, as well as the time periods in which the proximal processes take place (cf. Bronfenbrenner \& Morris, 1998). It could be speculated that, in a control population (i.e., in children without heightened risk for language problems), variation in children's early tendency to be drawn toward and maintain interest in joint language- and literacy-related activities is reflected in their vocabulary growth. At a later age, the variation in the amount of shared reading, on the other hand, has an effect on vocabulary growth in both groups. However, the association between environmental factors, children's interest, and skill development is reciprocal in nature, and children's skills may also affect how interested they become in reading activities and how much parents read with them. Thus, it can be speculated that for some children in the at-risk group the assumed core deficits or related underlying processes in phonological processing may interfere with or prevent the building of interest in shared reading activities and also hinder the accumulation of vocabulary. This interpretation is in line with suggestions that variation in phonological awareness may be more strongly associated with genetic vulnerability/strengths than with environmental variation.

The literature sees the ability to attend to the sub-word segments and to manipulate them in the mind (i.e., phonological awareness) as the core prerequisite skill that underlies the child's ability to grasp the principle of grapheme-phoneme correspondence and consequently to decode text. We have assessed phonological awareness (skill domain seven) on an annual basis during the ages 3.5 to 6.5 years using both traditional procedures and assessment in a computer context using animations. In the modeling, we 
used only composite scores of phonological awareness that are highly predictive of early reading, as shown by our recent paper (Puolakanaho, Poikkeus, Ahonen, Tolvanen, \& Lyytinen, 2004).

It should be noted that the dependent measure of our present analyses, the literacy composite, formed as an aggregate of early reading and spelling acquisition (which are highly correlated in Finnish due to symmetrical consistency; see Aro, 2006), reflects the children's progress in foundation-level reading in first and second grade. In the composite we used, the accuracy of decoding (and spelling) naturally receives a much stronger emphasis than the fluency of reading, which is not yet observable at its full strength at this grade level. Full accuracy is reached relatively early in consistent orthographies, and this means the speed (fluency) issue comes to the fore relatively soon after the start of reading instruction and continually plays a more central role in the assessment of reading skill thereafter. However, it should be noted that, because of the age of interest in the present analyses, issues of reading comprehension were not included in the composite score of reading. Some preliminary data on reading comprehension will, however, be provided for the description of the outcomes of developmental routes extracted from the pre-reading data.

Why, instead of waiting longer, should such an emphasis be placed on the early stage of reading and spelling? We believe that children define themselves as learners during the very first years at school, and the consequences of failure are far-reaching. A Finnish pupil who does not learn to decode accurately by the end of the first semester of first grade may almost unavoidably perceive him- or herself as different from others. This is because, in the Finnish schools, almost everyone progresses to highly accurate decoding skills within the first 4 months of reading instruction at the latest (Seymour, Aro, \& Erskine, 2003). The detrimental effects of comparing oneself unfavorably to others can have a general impact on one's learning strategies (mostly toward avoidance of challenging tasks) even as early as during first grade (Poskiparta, Niemi, Lepola, Ahtola, \& Laine, 2003).

With the aid of advanced statistical tools (mixture modeling), we carried out a novel analysis that combines person-centered and variable-centered analyses as it yields both continuous variables and a subcategorization of the participants. As both theoretical knowledge and the empirical evidence suggest strong correlations among the included language and literacy skill domains (receptive language, expressive language, morphology, memory, rapid naming, phonological awareness, and letter knowledge) and reading skills, we searched for a single, common factor that captures the shared variances of all the early measured language and literacy skills and the latermeasured components of reading. Simultaneously with the modeling of the 
common factor, we explored the children's individual trajectories from early language and literacy skills toward reading skill and identified groups of children with different types of developmental trajectories in our data set. By incorporating our numerous early language and literacy-based measures as composite variables into the mixture modeling technique, we hypothesize that not one, not two, but several developmental routes to early reading difficulties may be identified that differ by consequences to reading. Delays or deficits in the early development of phonological awareness and letter knowledge may compromise reading accuracy, whereas those in naming dysfluency may be more closely associated not only with acquisition of the foundation-level reading skills but also with the early automatization of reading. We are also interested to learn whether there are children among those with and without familial risk for dyslexia who do not manifest reading problems but whose early development contains signs of potential risk mentioned above - and vice versa, whether there are children whose reading acquisition starts abnormally but who do not show characteristics of a developmental risk and/or belong to the at-risk group.

\section{Method}

\section{Participants}

Data were drawn from the prospective Jyväskylä Longitudinal Study of Dyslexia (JLD). A total of 214 Finnish families joined the study prior to the birth of their children. Half of the participating families involved a parent who made a report of literacy difficulties and also reported similar problems among his or her immediate relatives (the children from these families are referred to as the at-risk children). The remaining half of the children (control children) came from families with no report of literacy difficulties among first- or second-degree relatives. In addition, the parents were screened and assigned to either group according to a three-step readingrelated and cognitive screening process (for further details, including parental education status, see Leinonen et al., 2001).

This study reports the data from 199 children (106 at risk, 93 controls for whom whole data were available) and extends from 12 months of age to the beginning of second grade.

\section{Measures}

As described above, a theoretical basis underpinned the selection of the seven core skill domains and age points of interest. Identification of the key 
measures in each skill area evolved from empirical analysis of the data. To ensure high reliability of the measures, composite means of separate measures were formed where possible. Table 1 details the seven developmental skill domains, assessment ages, standardized alpha produced for composite scores, and tasks included in the analysis.

Receptive language was assessed on 6 occasions between the ages of 12 months and 5 years. Early language tasks adapted from the MacArthur Communicative Development Inventory (CDI; Fenson et al., 1994) for the Finnish language (P. Lyytinen, 1999) relied upon structured parental report using checklists whereby parents noted the total number of words comprehended by their child. Measures of expressive language were derived on 7 occasions between 12 months and 5.5 years of age, again with the earlier measures involving parental checklist report of vocabulary production and maximum sentence length (mean number of morphemes uttered; for details of the assessment of vocabulary and inflectional skills using CDI, see P. Lyytinen \& Lyytinen, 2004). Morphological knowledge, including the ability to inflect adjectives, nouns, and verbs, was assessed 3 times between $2.5,3.5$, and 5.5 years. The assessment of memory relied upon traditional paradigms involving digits but was also expanded to include syllables, nonwords, and sentence-length items in the recall. Memory was assessed between the ages of 3.5 and 6.5 years on 4 occasions. Traditional paradigms (Denckla \& Rudel, 1974, 1976) for rapid serial naming were also used, including letters, objects, numbers, and colors. Mixed-stimulus paradigms were not included, although the matrix size was increased in accordance with age. Three blocks of rapid naming assessments took place between the ages of 3.5 and 6.5 years. Letter knowledge and associated letter recognition tasks were implemented on 5 occasions between the ages of 3.5 and 6.5 years. An extensive battery of tests of phonological awareness was implemented between the ages of 3.5 and 6.5 years. Tasks involved the manipulation and production of sub-word-level units (syllables and phonemes). At the age of 5 years, verbal and performance intelligence quotients were also obtained with a short-form administration of the Wechsler Preschool and Primary Scales of Intelligence (WPPSI-R; Wechsler, 1989).

In addition to the seven skill domains, a composite of the children's early reading and spelling achievement during their first school year and the beginning of the second school year (mid-fall assessment of second grade) was included in the comparison (see Table 2). The composite was formed by calculating a grand mean of scores. The battery of tests included computerized tests (Cognitive Workshop, Universities of Dundee and Jyväskylä; see Erskine \& Seymour, 2005, for extensive implementation), tests with national norms (Lindeman, 2000), and specially designed group 


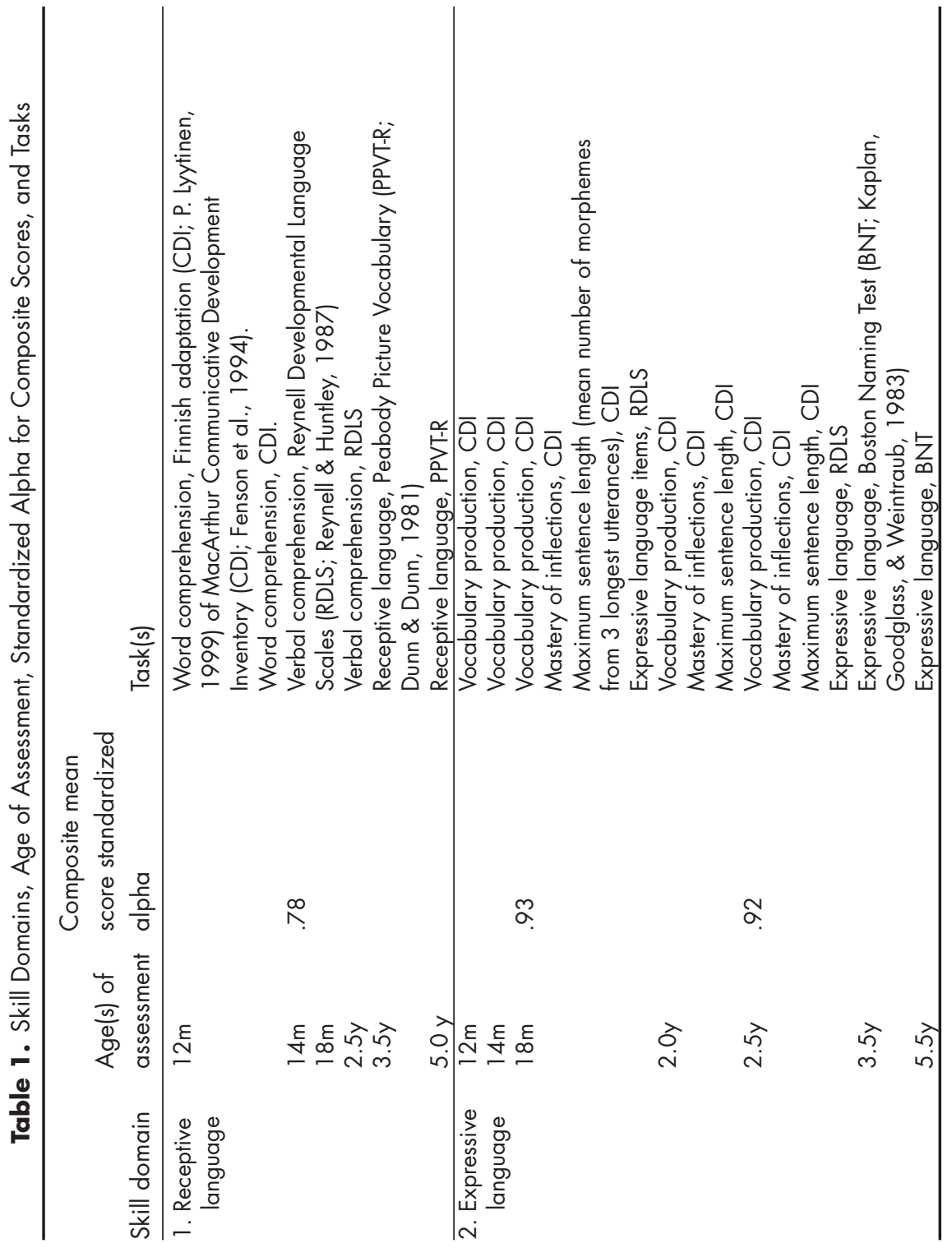




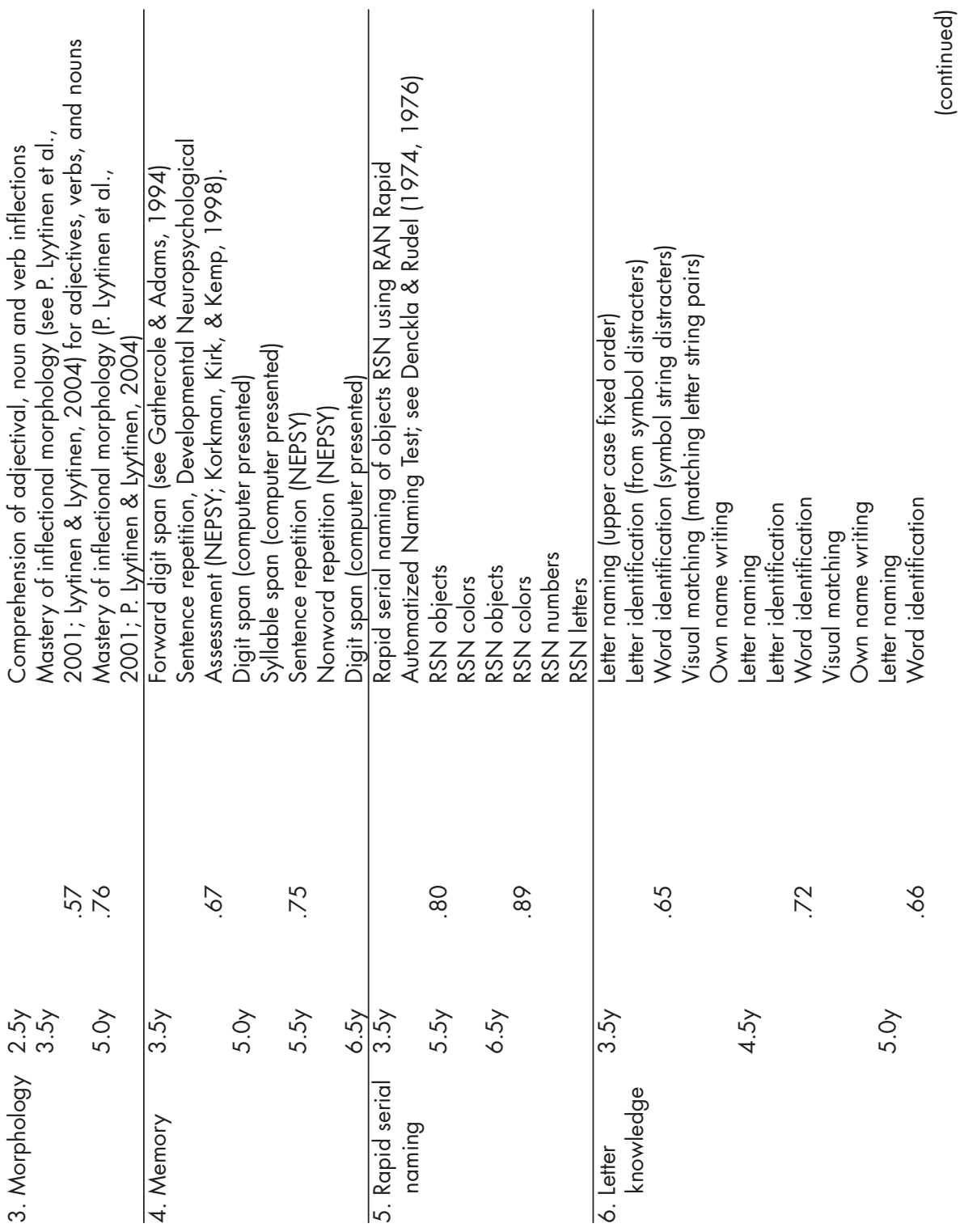




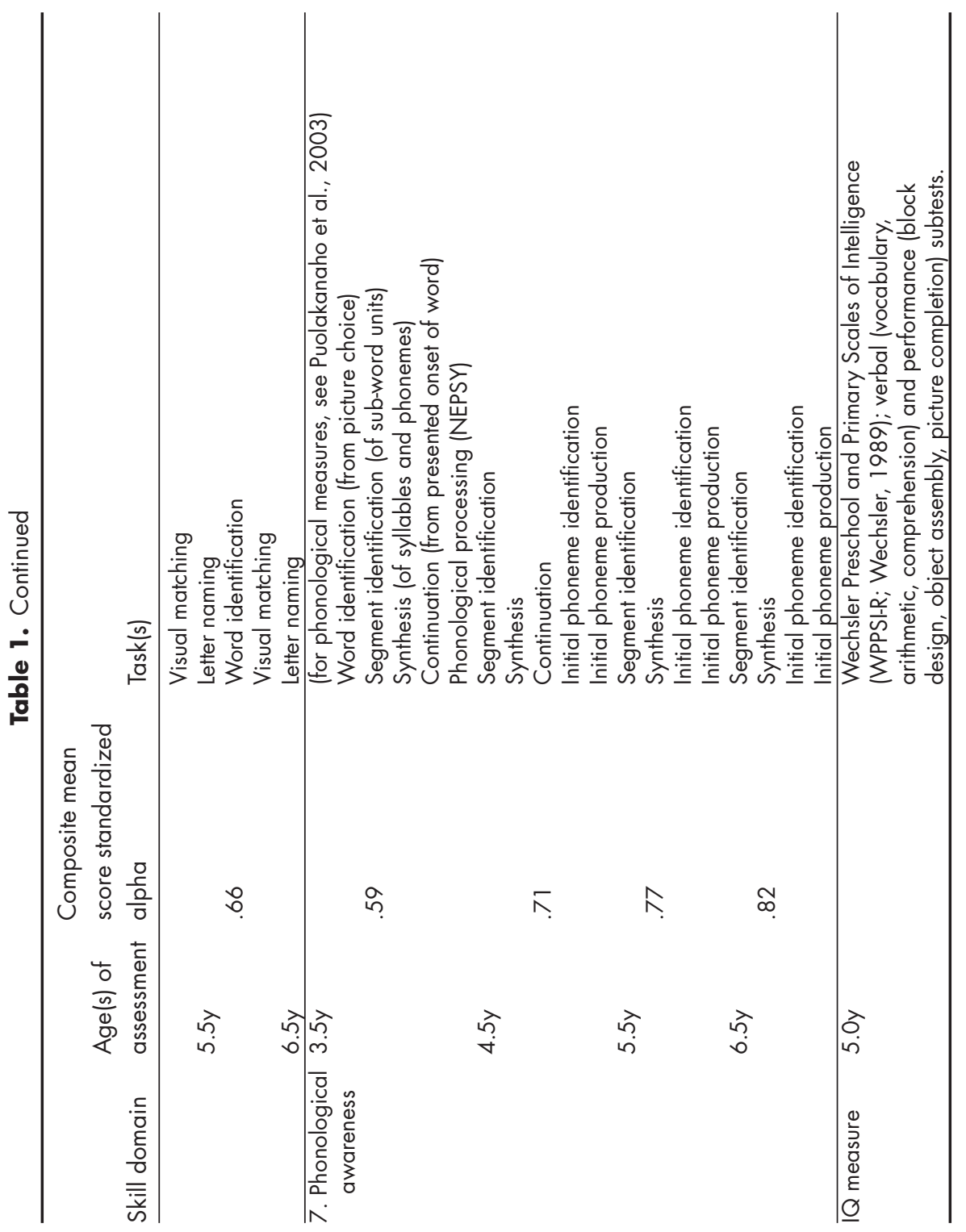




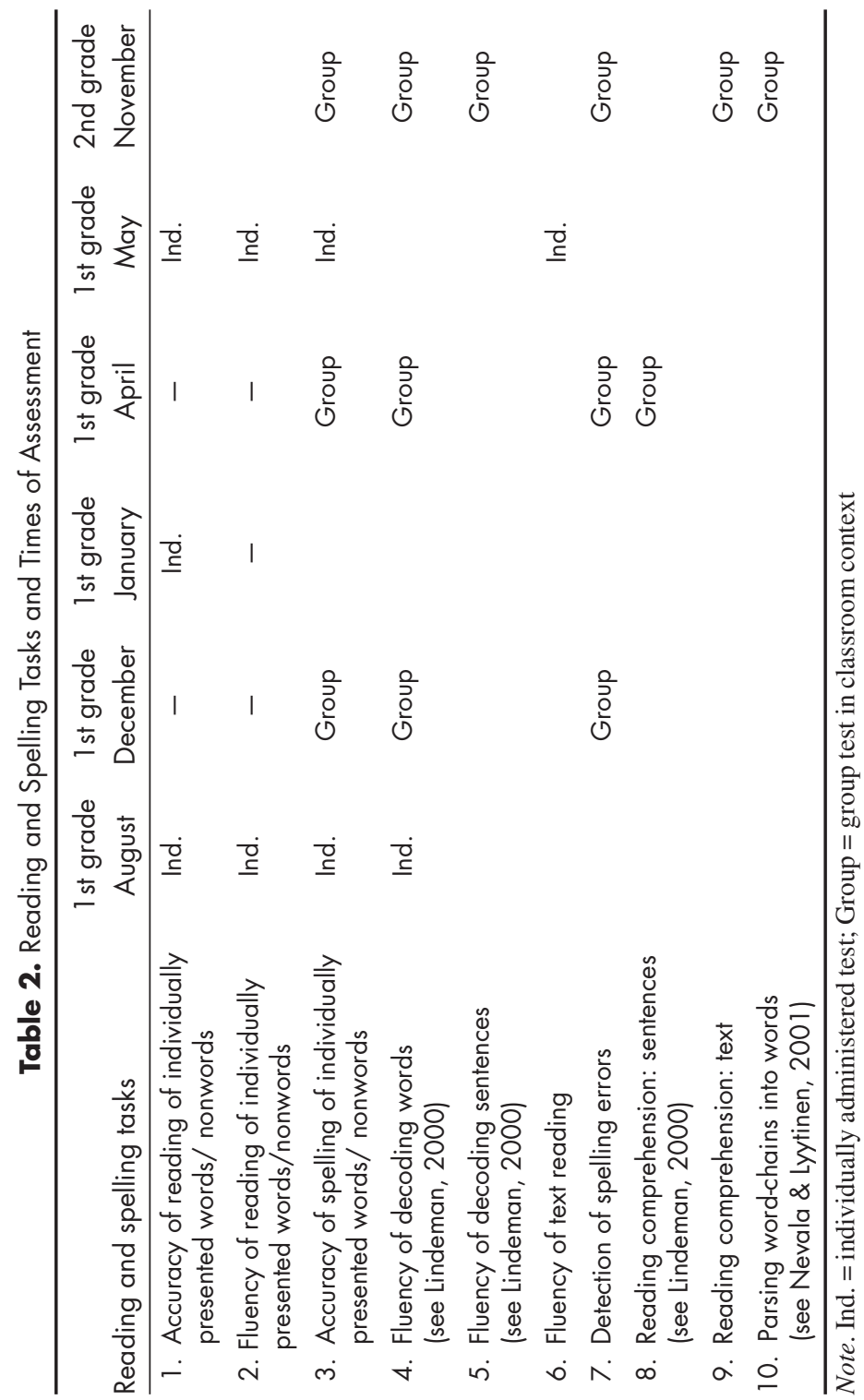


tests (Nevala \& Lyytinen, 2001). The assessments (type and time point) are detailed in Table 2.

\section{Statistical Approach}

The modeling consisted of two parts: identification of a latent common factor and a latent class factor. Based on theoretical knowledge and the empirical evidence suggesting strong correlations among the variables in the seven domains, an underlying common factor was assumed, and this type of latent factor was included in the construction of the model. The latent common factor extracts the common variance shared by individuals in the seven skill domains introduced above (receptive language, expressive language, morphology, memory, rapid serial naming, letter knowledge, and phonological awareness). The analysis of a common factor helps us to ascertain the extent to which a single skill domain is associated with compromised reading acquisition as well as what type(s) of developmental variation emerges as separable from this main line.

The second part of the model, the latent class factor, isolates the most homogeneous patterns of an individual's development, thus showing which of the differential patterns of development is connected to problems in early reading acquisition. Our preliminary findings indicate that approximately $40 \%$ to $50 \%$ of the at-risk children display compromised reading development during the first two school years (formal diagnosis of dyslexia must await all cohorts of our participants completing third grade). The data thus contain the necessary variation to allow us to observe possible differential patterns of levels and/or rates of skill development and cases of dissimilar but predictable developmental courses. With this combination of latent classes and latent factors we sought to apply person-oriented analysis of data (e.g., trajectories of latent classes) in addition to variable-oriented analysis (e.g., explain variances and covariances of observed variables with latent common factors; cf. Bergman, Magnusson, \& El-Khouri, 2003).

We used the mixture modeling feature of the MPLUS (version 3) program (L. K. Muthén \& Muthén, 2004) to analyze the repeatedly measured variables included under the seven skill domains. Mixture modeling allowed us to examine simultaneously both the common factor and the individual patterns of development by identifying clusters of children who show similar trajectories. In construction of the model, one has the option to apply latent classes with distinct mean values of observed variables or of latent factors (B. Muthén, 2001). We studied both of these alternatives, and the data supported the former option, which yields a model in which the latent underlying skill factor and the latent classes are independent sources 
of variation in the observed variables. To evaluate the number of latent classes we have used three criteria: AIC (Akaike's information criteria), BIC (Bayesian information criteria), and adjusted BIC and Lo-MendelRubin test (Lo, Mendell, \& Rubin, 2001). The lower AIC, BIC, or adjusted BIC indicate a better model, and significant Lo-Mendel-Rubin test results indicate a higher number of groups. The model was estimated using the MLR (maximum likelihood method with robust standard errors) method, and missing values (missing at random) were handled via MPLUS that uses an EM (expected maximum) algorithm.

\section{Results and Discussion}

Table 3 summarizes the mixture model estimates. The table reveals the common factor loadings with standard error values. It shows how much each variable shares variance $\left(\mathrm{R}^{2}\right)$ with the common factor and with the subgrouping solution (classes), as well as the unexplained error referring to the within-group individual variation.

A closer inspection of the numbers reveals that most of the variables selected to predict reading acquisition have relatively high loadings with the common factor; explanation varied from 5\% of RAN to $62 \%$ of letter knowledge scores from assessments carried out at the age of 5.0 years. This factor reflects the variance that is common between the measures with the weights or percentages $\left(\mathrm{R}^{2}\right)$ given in Table 3 . This makes the labeling of this common factor interesting.

To elaborate upon its nature, the contribution of IQ was further examined by fixing the parameters of the preceding model and by adding the performance IQ and verbal IQ scores into the model. This analysis revealed that performance IQ had only $25 \%$ of common variance and the error (the contribution of the individual variation) was high (74\%), meaning that it does not belong to the common factor. The shared variance of the common factor and the verbal IQ was 44\%, and $45 \%$ of the variation in verbal IQ was due to individual variation. Furthermore, the subgrouping was associated with neither IQ (shared variance was $1 \%$ with performance IQ and $11 \%$ with verbal IQ). Thus it was mainly the verbal component of IQ that was associated with the common factor.

It is apparent that the common factor represents the skills closely related to reading that are available before acquisition of reading, first of all orthographic skills such as letter knowledge $\left(\mathrm{R}^{2}=43-76 \%\right)$ and phonological awareness $\left(\mathrm{R}^{2}=33-52 \%\right)$, that is, the interest and ability of the child to attend to and manipulate in the mind the sub-word-level speech sounds. The early reading skill itself also has a high loading $\left(\mathrm{R}^{2}=41 \%\right)$. Thus, we 
Table 3. The Latent Mixture Model Estimates; Factor Loadings for the Common Factor (standard errors are presented in parenthesis), and sources of variance for the Observed Variables $\left(\mathrm{R}^{2}\right)$

\begin{tabular}{|c|c|c|c|c|}
\hline & \multirow{2}{*}{$\begin{array}{l}\text { Common } \\
\text { factor } \\
\text { loadings (se) }\end{array}$} & \multicolumn{3}{|c|}{$R^{2}$} \\
\hline & & Common & Classes & Error \\
\hline \multicolumn{5}{|l|}{ Receptive language } \\
\hline Age $1.0-1.5$ years & . $35(.07)$ & .13 & .10 & .77 \\
\hline Age 2.5 years & $.62(.07)$ & .34 & .23 & .43 \\
\hline Age 3.5 years & $.53(.08)$ & .29 & .16 & .54 \\
\hline Age 5.0 years & $.59(.07)$ & .29 & .13 & .59 \\
\hline \multicolumn{5}{|l|}{ Expressive language } \\
\hline Age 1.5 years & $.34(.07)$ & .14 & .09 & .77 \\
\hline Age $2.0-2.5$ years & $.43(.06)$ & .18 & .18 & .64 \\
\hline Age 3.5 years & $.52(.07)$ & .26 & .28 & .46 \\
\hline Age 5.5 years & $.65(.10)$ & .31 & .14 & .55 \\
\hline \multicolumn{5}{|l|}{ Morphology } \\
\hline Age 2.5 years & . $34(.08)$ & .10 & .23 & .66 \\
\hline Age 3.5 years & $.50(.07)$ & .23 & .21 & .56 \\
\hline Age 5.0 years & $.44(.08)$ & 17 & .12 & .70 \\
\hline \multicolumn{5}{|l|}{ Phonological awareness } \\
\hline Age 3.5 years & $.61(.08)$ & .33 & .06 & .62 \\
\hline Age 4.5 years & $.74(.10)$ & .41 & .12 & .47 \\
\hline Age 5.5 years & $.88(.12)$ & .50 & .15 & .36 \\
\hline Age 6.5 years & $.81(.12)$ & .52 & .21 & .27 \\
\hline \multicolumn{5}{|l|}{ Letter knowledge } \\
\hline Age 3.5 years & $.58(.07)$ & .43 & .02 & .55 \\
\hline Age 4.5 years & $.83(.06)$ & .61 & .05 & .34 \\
\hline Age 5.0 years & .76 (.06) & .62 & .09 & .29 \\
\hline Age 5.5 years & $.87(.06)$ & .61 & .12 & .27 \\
\hline Age 6.5 years & $.76(.10)$ & .53 & .16 & .31 \\
\hline \multicolumn{5}{|l|}{ Short-ferm memory } \\
\hline Age 3.5 years & $.53(.06)$ & .28 & .20 & .52 \\
\hline Age 5.0 years & $.59(.07)$ & .32 & .18 & .51 \\
\hline Age 6.5 years & $.48(.07)$ & .20 & .04 & .76 \\
\hline \multicolumn{5}{|l|}{ Rapid naming } \\
\hline Age 3.5 years & $.40(.07)$ & .18 & .04 & .78 \\
\hline Age 5.5 years & $.35(.10)$ & .05 & .52 & .44 \\
\hline Age 6.5 years & .67 (.09) & .18 & .41 & .41 \\
\hline $\begin{array}{l}\text { Overall reading composite, } \\
\text { Grades } 1-2\end{array}$ & $.71(.12)$ & .41 & .19 & .40 \\
\hline
\end{tabular}


could label it the general reading readiness factor. That the foundation skills of speech perception are involved in the common factor is reflected in up to $34 \%$ of shared variance with receptive language and the association with verbal IQ (44\%).

In the mixture analysis of the seven skill domains and early literacy, solutions of 2-7 subgroups were identified based on the criteria indices and test provided by MPLUS. Our decision to examine more closely the solution with four subgroups was based on the theoretical consideration and interpretability of the alternative solutions provided by the modeling. The average scores for probabilities of individual group membership (see Table 4) detail the differentiation of the groups, revealing that the four-group solution provided an excellent separation. Each of the four subgroups had only one high $(>.90)$ average probability of group membership value, and none of the groups overlapped with any other, as expressed by probabilities of less than .10.

The subgroup classification information in addition to the common variance explains $4-52 \%$ (mostly $10-20 \%$ ) of the variance of the single skill scores. As can be seen from Table 3, the naming domain makes a relatively high specific contribution (up to $52 \%$ ) to the subgroup classification but contributes very little to the common factor.

\section{The Developmental Trajectories to Reading}

Figure 1 summarizes the profiles of the four subgroups (named as representing declining, typical, dysfluent, and unexpected trajectories) as a function of the seven skill domains relative to early literacy ability (the last

Table 4. Classification Table of the Average of the Individual Group Membership Probabilities (columns) Into Most Likely Subgroup (rows)

\begin{tabular}{lcccc}
\hline & $\begin{array}{c}\text { Subgroup 1 } \\
\text { (declining) }\end{array}$ & $\begin{array}{c}\text { Subgroup 2 } \\
\text { (typical) }\end{array}$ & $\begin{array}{c}\text { Subgroup 3 } \\
\text { (dysfluent) }\end{array}$ & $\begin{array}{c}\text { Subgroup 4 } \\
\text { (unexpected) }\end{array}$ \\
\hline $\begin{array}{l}\text { Subgroup 1 } \\
\text { (declining) }\end{array}$ & .907 & .058 & .000 & .035 \\
$\begin{array}{l}\text { Subgroup 2 } \\
\text { (typical) }\end{array}$ & .049 & .937 & .000 & .014 \\
$\begin{array}{l}\text { Subgroup 3 } \\
\text { (dysfluent) }\end{array}$ & .000 & .002 & .996 & .002 \\
$\begin{array}{l}\text { Subgroup 4 } \\
\text { (unexpected) }\end{array}$ & .017 & .014 & .002 & .966 \\
\hline
\end{tabular}


score in the figure). Interpretation of an individual profile belonging to a subgroup requires recognition of the fact that one's profile comprises the subgroup-specific developmental (time- and domain-related) variations and the child's position in the reading readiness factor (according to the common factor loadings given in Table 3).

Declining trajectory. Children in the "declining trajectory" subgroup (subgroup $1 ; n=35$ ) shared an interesting characteristic: relative to the others, their position decreased continuously in most skill domains, the only exception being naming speed. This type of developmental pattern seems to be more common among children who are at familial risk for dyslexia (only $12 \%$ of control children compared to $23 \%$ of at-risk children belonged to this subgroup). More than half of the at-risk children and about $40 \%$ of the control children belonging to this subgroup showed problems in early reading acquisition and in attaining a sufficient level of reading speed for reading comprehension. About $20 \%$ of the children with the "declining trajectory" (both controls and children at risk) continued to show problems in reading or spelling accuracy at the end of first grade, and even more showed problems in the development of reading fluency. Only 2 of the con-

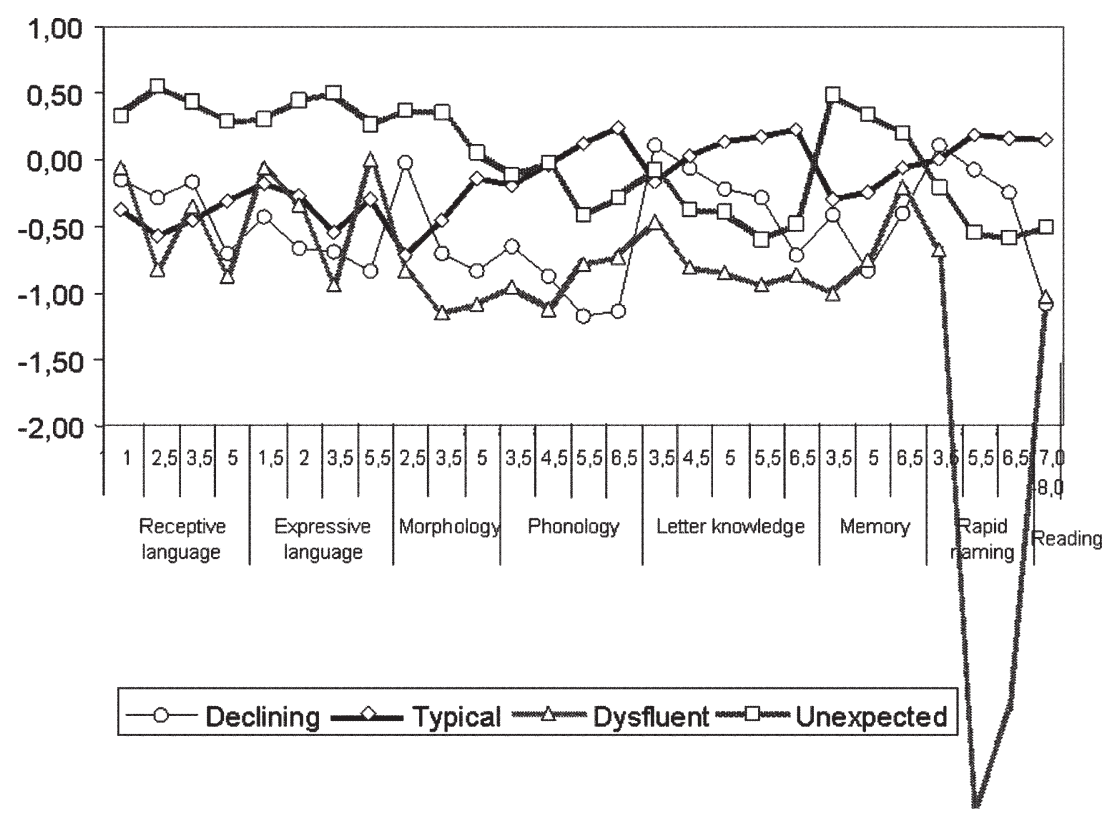

Figure 1. Subgroup members' average performance in the seven skill domains (across age from 1 to 6.5 years) and in the reading and writing skills composite (across first and second grade). Mean values are z-scored with the control children's distribution. 
trol children (compared to 12 children at risk) showed reading comprehension problems at the end of first grade. A large proportion of children in this subgroup lagged behind the average reading skill level during the end of first grade, culminating in the fact that the average overall reading achievement across first and second grade was lowest in this subgroup (-.68 expressed as the mean $z$-score). However, at the same time, this group showed the highest within-group variation, differentiating members who are control children from those who are at risk, as shown by Figure 2.

Typical trajectory. The members of the largest subgroup (subgroup 2; $n=85$, of which $55 \%$ were control children) were proficient in all reading-

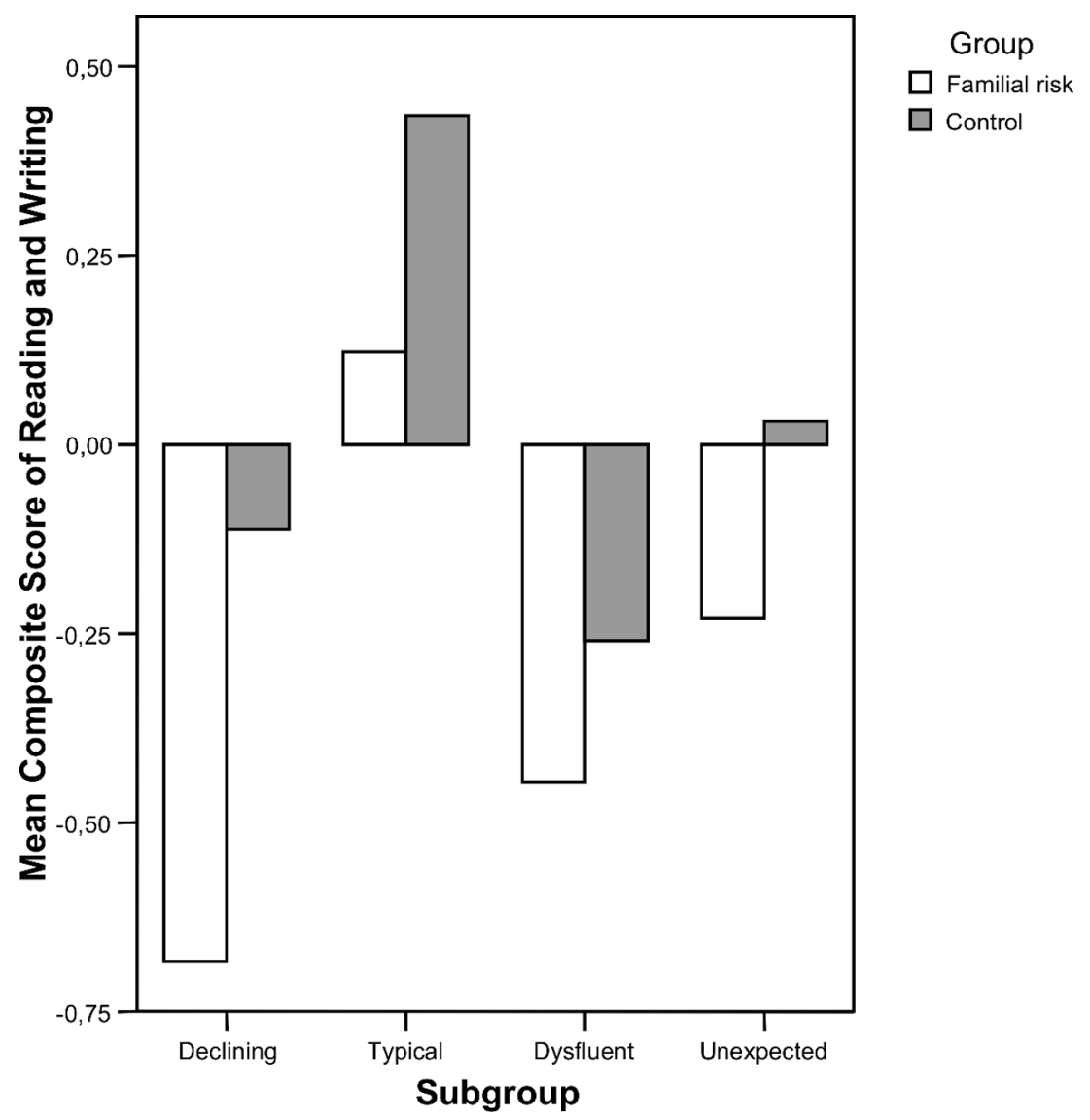

Figure 2. The subgroups' average performance in general composite of reading and writing skills at first and second grade separately for the children at familial risk and control children. Mean values are $z$-scored with control children's distribution. 
related developmental skill domains, such as phonology and letter knowledge. They showed continuous elevation of their mean relative skill position across the development, which made them clearly the most skilled group prior to school entry. Due to the common characteristic of this group to show progressive skill development in relation to children whose developmental progressing is somehow compromised, we labeled this group as following a "typical trajectory." Very few of the children belonging to this group showed any reading problems, and those few who did so showed some delay only at the very beginning of school or showed low scores in comprehension. This subgroup, thus, collected most good readers from both groups. The fact that more than one third of the at-risk children belonged to this group despite the genetic risk could be attributed to the fact that not more than half of the children in the at-risk group are expected to have any problems due to genetic vulnerability (only one parent affected) and also to increased attention that participation in a longitudinal study provides in support of reading-related development.

Dysfluent trajectory. Children in the smallest subgroup (subgroup 3; $n=12$, all except 1 of the children being at risk for dyslexia) differ dramatically from all others by showing naming speed problems. The common characteristic of the members of this subgroup demarcated them as following a "dysfluent trajectory." The second striking characteristic of children in this subgroup is that their relative scores tend to decrease as a function of age in most domains (see Figure 1), with the exception of phonological skills (which maintain their level) and verbal short-term memory (which shows a rather clear trend toward better relative performance). A third characteristic of this subgroup is that the children's mean skill level across ages is, with the exception of expressive language, poorest in all domains. However, as Figure 2 shows, the general composite score of reading for this subgroup is only second poorest, although, as expected and as will be seen later, this group's reading rate was the lowest by far. This lower performance in reading speed also persisted during the first two school years. It is important to note that reading instruction was relatively successful in promoting the reading accuracy (but not fluency) of these children.

Unexpected trajectory. The members of the fourth subgroup $(n=67$; $51 \%$ were at-risk children) were relatively strong in their early language (in receptive and expressive speech) and in their general language skills, such as morphology, and their memory skills were better than that of the other groups. Surprisingly, in spite of these strengths, the mean letter knowledge scores for the children in this subgroup were low and relatively declining across ages, and many of the children encountered problems, especially in the early acquisition stages of reading. The below-mean letter knowledge before school entry seemed to be reflected in the reading acquisition in this 
group. This shows the immediate connection of the development of letter knowledge to reading in a consistent orthography. The common characteristic of children in this subgroup seems to be that they were proficient in everything else assessed in this study but not in the domains most closely associated with reading. This finding is very unexpected, because these children's spoken language skills were atypically high in comparison to the others and to their reading skill. Accordingly, we named this subgroup as "unexpected," which describes how many of these children were compromised early readers independent of good language skills and memory. It is important to note that the non-optimal reading acquisition was not specific to the at-risk members of this subgroup.

\section{Predicting Reading on the Basis of the Combined Variable-Centered and Person-Centered Model}

When the trajectories of latent classes and the common factor are unrelated, they both contribute independently toward the prediction of reading. We therefore examined the prediction value provided by these two model components to the outcome measure of the overall reading skill composite.

In Figure 3 we fixed the contribution of the common factor between -1 $S D$ and $+1 S D$ and computed the total prediction of reading in each subgroup, taking into account this variation in the common factor. Within this range of common factor variation, predicted $z$-values of reading skills in the "declining trajectory" varied between -1.79 and -.37 (mean value -1.08 ), which is very similar to the respective values of the "dysfluent trajectory," both thus being quite predictive of problems in reading acquisition. The values of the children following a "typical trajectory" varied around zero and were above that of the declining and dysfluent children, while the atypical early readers with good spoken language skills (unexpected) were almost at the same level with the dysfluent and declining children. Consequently, based on both the classification and general reading readiness (common) factor, we were able to find three different routes to compromised reading acquisition in the sense of reading below normal level.

\section{The Role of Familial Risk Requires Further Scrutiny}

One cannot totally exclude the possibility that the risk factor may still exert some effects that we did not observe or that the model was not optimized for prediction. In a regression analysis that predicted the overall reading composite with the membership of the at-risk group and controlled for subgrouping and common factor score, familial risk still explained $3 \%$ of the variation of the reading composite, $F(1,192)=5.87, p=.016$. Of the 38 at-risk children 


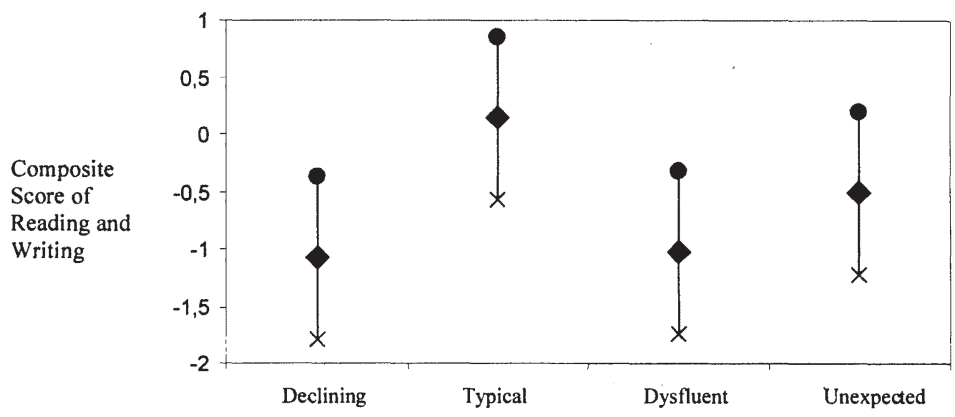

- Group average in overall reading and writing composite

$x$ Predicted/expected value of the overall reading and writing composite within subgroups when the value of the common factor is set to be $1 S D$ below its mean value.

- Predicted/expected value of the overall reading and writing composite within subgroups when the value of the common factor is set to be $1 S D$ above its mean value.

Figure 3. The prediction of the overall performance in reading and writing skills (z-scored with control children's distribution) provided by the model estimates of subgrouping and the common factor. Common factor values were here restricted to 1 SD around the mean.

belonging to the subgroup with typical trajectory, 7 (and 1 of the 47 control children) had a slow start in their reading career in terms of learning to read later than others. In addition, 8 at-risk children (compared to 2 controls) in this subgroup scored $1 S D$ below the control children's mean in reading comprehension at the end of first grade. We may accept that, among typical children, a small minority may get off to a slow start and experience comprehension problems. It could be argued that such children may flourish if educators pay attention (during school) to that domain of development.

\section{Is Reading Acquisition Predicted by Different Developmental Paths of Language Development?}

To obtain a more detailed picture concerning the prediction of reading development, we analyzed the predictors separately for (1) the early reading seen in the combined accuracy and fluency measures/scores at the beginning of first grade, (2) spelling during the beginning of first grade and the end of first grade, (3) reading accuracy at the end of first grade, (4) reading fluency at the end of first grade, and (5) comprehension at the end of first grade. 
Figures 4 and 5 summarize the percentages of children from each group scoring $1 S D$ below the mean of the control children on each dependent measure of interest. These figures reveal that the highest proportion of delayed readers are at familial risk and additionally belonged either to the "dysfluent" or "declining" trajectory subgroups. More than half of these children were slow to acquire basic reading skills, while in both of these subgroups roughly the same proportion of children remained delayed in comprehension (for a more detailed analysis of predictive relationships between receptive language and reading comprehension, see also P. Lyytinen, Eklund, \& Lyytinen, 2005). Progress in early reading acquisition was slow among the control children belonging to these two subgroups, but the proportion of control children belonging to these two subgroups was much lower $(12 \%)$ than the proportion of children at familial risk (33\%). Note that only one control child showed a "dysfluent trajectory." This suggests that, within a consistent orthography, dysfluency is especially implicated in reading from a genetic standpoint, supporting the contention by Wimmer, Mayringer, and Landerl (2000) and earlier Finnish findings by Korhonen (1995) that dysfluency may be the most persistent feature of dyslexia. It must be noted that both of these findings emerge from an orthography where reading accuracy is attained relatively early and apparently with more ease (Aro \& Wimmer, 2003; Seymour et al., 2003) than can be expected from readers of an orthography that demands the learning of more complex systems of letter-sound connections.

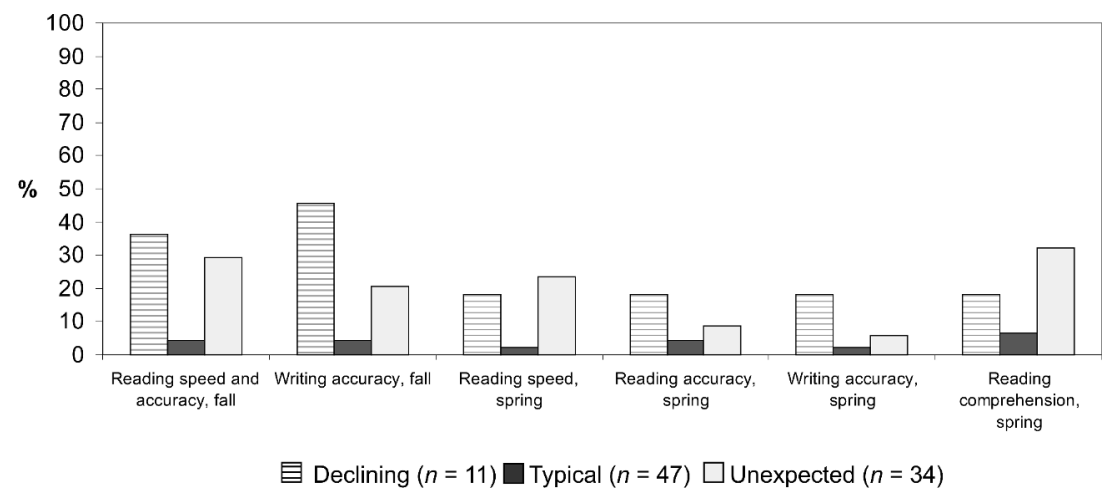

Figure 4. Percentages of the control children performing more than 1 SD below control children's mean in first-grade reading and writing skills within each subgroup. Because only one child belonged to the dysfluent subgroup, the related percentage was not included in the figure. 


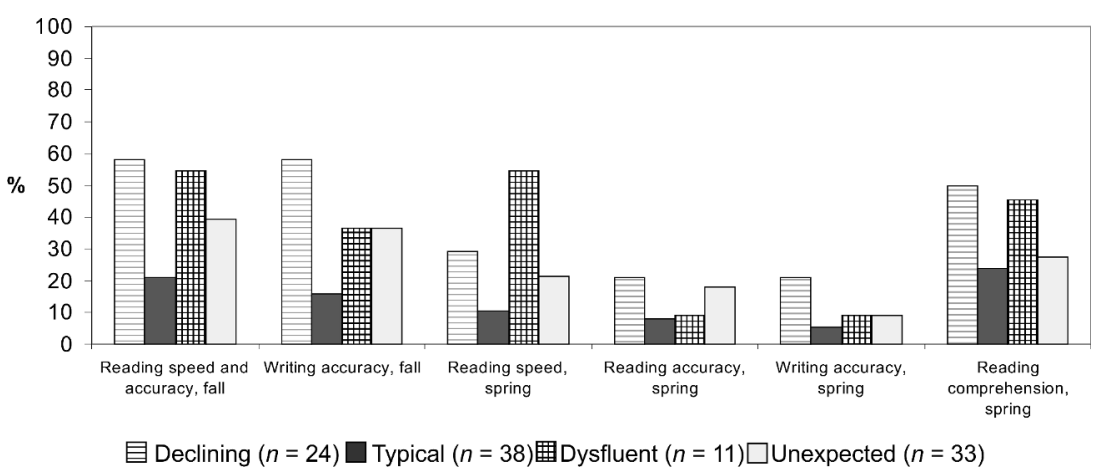

Figure 5. Percentages of the familial-risk children performing more than 1 SD below control children's mean in first-grade reading and writing skills within each subgroup.

As Figures 4 and 5 show, the children following "dysfluent" and "declining" trajectories were also delayed at the end of first grade, but by this time there was a clear differentiation between accuracy and speed. Rate of reading was the main impairment in the dysfluent subgroup of the at-risk children, while not more than $20 \%$ of both familial-risk and non-risk members of the "declining" trajectory had persistent difficulties in both rate of reading and accuracy, as observed in both reading and spelling. The consequences of these impairments were, however, different for the at-risk children and the non-risk children: almost twice the number of at-risk children had problems in comprehension than did the control children in this "declining" subgroup.

The fate of those who are atypical readers but skilled speakers (the "unexpected" subgroup) is interesting. Although the proportions of control and familial-risk children were equal, the incidence of at-risk children showing delayed acquisition of accurate reading was almost twice that of the control children. The development of reading speed remained delayed in both control and familial-risk children, while accuracy in both reading and spelling increased quickly, especially among controls. A surprising observation was that the proportions of delayed comprehenders within this subgroup were relatively similar (>20\%) in both groups.

\section{Concluding Remarks}

The main finding of the present analysis is that there is substantial interindividual variation, not only between the groups of children differing on the basis of familial background, but also within these groups. A substantial part of this variability was anticipated by the children's skill development 
prior to formal reading instruction. We were able to document a new aspect almost untouched in the earlier literature; that is, it may be the trend of the development that is predictive rather than the level profile. Thus, some children who commenced with a relatively high level but had a declining trend of development were among the poorest readers. It also shows that very early detection may not always be possible. A small number of our children showed their first signs of risk relatively late.

The manifestations of risk in skill development among the children at familial risk are clearly divided into two developmental profiles. One is characterized by dysfluency, covering both spoken naming and reading speed. The other profile is low and relatively declining achievement relative to the mean level throughout most skill domains, but most clearly in phonological awareness and letter knowledge, which are known to be the closest predictive associates of early reading. Slow growth of letter knowledge seems to be a strong predictor of poor reading acquisition, independent of familial risk.

We observed a number of surprises in our findings. The most dramatic one is that early optimal development of receptive and expressive language does not always predict early reading, and in fact, sometimes an abnormal course of literacy development may ensue. Some of the children whose initial spoken-language skills were above the mean nevertheless manifested less optimal progress in early reading, which was accompanied by a dramatic relative drop in their development of letter knowledge from the beginning level at age 3.5 years to the months before school entry. It may be that these children's better-than-average early spoken language skills resulted in a relatively lower amount of attention from adults with regard to providing environmental support and instruction for the child in learning letters and phonological skills. This type of effect is especially pertinent to children who are at biological risk for dyslexia. A relatively strong correlation between supportive aspects of the home literacy environment and development of phonological awareness skills has, in our previous analyses, been observed to be effective for at-risk children but not for control children (Torppa et al., submitted).

In the present data set we did not include measures that could have reflected development in non-language domains such as motor skills (described by Fawcett \& Nicolson, 1995), although this type of co-occurrence is possible (for preliminary findings from our study, see H. Lyytinen, Ahonen, et al., 2004). We have very recently analyzed our data collected from the motor domain and found support for its potential role in the early developmental risk profile of a subgroup of children by detecting an early motor delay that is associated with language development and a delay in acquiring fluent reading skill (Viholainen et al., 2006). 
With respect to general practical implications, our findings indicate that a relatively comprehensive assessment of development is required in order to detect, as early as possible, all or even most of the children who may have problems in reading acquisition. The detection rate is clearly better and follows a more expected pattern among children who have family members with reading problems - a predictive sign that is easy to take into account.

In this study we concentrated on early acquisition of reading and writing, mainly early decoding skills. The ultimate goal—fluent reading with complete comprehension-received only minor attention due to the age of the children. We are as optimistic as Vellutino et al. (2004) in our belief that almost everyone can be helped to attain accurate reading skill. However, the time and practice required for this achievement varies greatly between individuals. What is less clear today is whether dysfluency (slow reading), which appears to be common to both naming and reading, can be helped to the same extent (for recent reviews, see H. Wimmer et al., 1998; Wolf, Bowers, \& Biddle, 2000). It appears that the fluency attained in normal reading development is especially difficult to achieve among individuals with dyslexia in consistent orthographies. In contrast, accuracy, which has also received most attention in the research, especially in less consistent orthographies such as English, presents a significant challenge to readers of such orthographies.

Based on the present findings, we can speculate that susceptibility for difficulties in the higher cognitive aspects of reading with comprehension likely has its roots in more foundational aspects of reading skill as expressed in indices of fluency. Fluency measures may merit a stronger emphasis in the prediction of achievements in reading comprehension. Thus, in addition to the assessment of phonological skills (not forgetting the child's readiness to acquire letter knowledge), naming speed also merits attention. Together, these measures are likely to provide relevant prognostic data for development in processing text with comprehension, which is often compromised in conjunction with early acquisition of basic reading skill.

\section{References}

Adams, M. J. (1990). Beginning to read: Thinking and learning about print. Cambridge: MIT Press.

Aro, M. (2006). Learning to read: The effect of orthography. In R. M. Joshi \& P. G. Aaron (Eds.), Handbook of orthography and literacy (pp. 531-550). Hillsdale, NJ: Erlbaum.

Aro, M., \& Wimmer, H. (2003). Learning to read: English in comparison to six more regular orthographies. Applied Psycholinguistics, 26, 619-634. 
Beauvois, M. F., \& Derouesné, J. (1979). Phonological alexia: Three dissociations. Journal of Neurology, Neurosurgery and Psychiatry, 42, 1115-1124.

Bergman, L. R., Magnusson, D., \& El-Khouri, B. M. (2003). Studying individual development in an interindividual context: A person-oriented approach. Vol. 4 of Paths through life (D. Magnusson, Series Ed.). Mahwah, NJ: Erlbaum.

Bradley, L., \& Bryant, P. E. (1983). Categorising sounds and learning to read: A connection. Nature, 301, 419-421.

Bronfenbrenner, U., \& Morris, P. A. (1998). The ecology of developmental processes. In W. Damon (Ed.), Handbook of child psychology. Vol. 1: Theoretical models of human development (5th ed., pp. 993-1028). New York: Wiley.

Byrne, B. (1998). The foundation of literacy: The child's acquisition of the alphabetic principle. Hove, UK: Psychology Press.

Coltheart, M., Masterson, J., Byng, S., Prior, M., \& Riddoch, J. (1983). Surface dyslexia. Quarterly Journal of Experimental Psychology, 35A, 469-495.

DeJong, P., \& Olson, R. K. (2004). Early predictors of letter knowledge. Journal of Experimental Child Psychology, 88(3), 254-273.

DeJong, P., \& Vrielink, L. O. (2004). Rapid automatic naming: Easy to measure, hard to improve (Quickly). Annals of Dyslexia, 54, 65-88.

Denckla, M. B., \& Rudel, R. G. (1974). Rapid “automatized" naming of pictured objects, colors, letters and numbers by normal children. Cortex, 10, 471-479.

Denckla, M. B., \& Rudel, R. G. (1976). Rapid "automatized" naming (R.A.N.): Dyslexia differentiated from other learning disabilities. Neuropsychologia, 14, 471-479.

Dunn, L. M., \& Dunn, L. M. (1981). Peabody Picture Vocabulary Test-Revised. Circle Pines, MN: American Guidance Service.

Elbro, C., Borstrøm, I., \& Petersen, D. K. (1998). Predicting dyslexia from kindergarten: The importance of distinctness of phonological representations of lexical items. Reading Research Quarterly, 33, 36-60.

Erskine, J. M., \& Seymour, P. H. K. (2005). Proximal analysis of developmental dyslexia in adulthood: The cognitive mosaic model. Journal of Educational Psychology, 97(3), 406-424.

Fawcett, A. J., \& Nicolson, R. I. (1995). Persistent deficits in motor skill of children with dyslexia. Journal of Motor Behavior, 27, 235-240.

Fenson, L., Dale, P. S., Reznick, J. S., Bates, E., Thal, D., \& Pethick, S. J. (1994). Variability in early communicative development. Monographs of the Society for Research in Child Development, 59 (5, Serial No. 242).

Fowler, A. E. (1991). How early phonological development might set the stage for phoneme awareness. In S. A. Brady \& D. P. Shankweiler (Eds.), Phonological processes in literacy (pp. 97-117). Hillsdale, NJ: Erlbaum.

Gallagher, A. Frith, U., \& Snowling, M. J. (2000). Precursors of literacy delay 
among children at genetic risk of dyslexia. Journal of Child Psychology and Psychiatry, 41, 203-213.

Gathercole, S. E., \& Adams, A.-M. (1994). Children's phonological working memory: Contributions of long-term knowledge and rehearsal. Journal of Memory and Language, 33, 672-688.

Gathercole, S. E., \& Baddeley, A. D. (1997). Sense and sensitivity in phonological memory in vocabulary development (A reply to Bowey, 1996). Journal of Experimental Child Psychology, 67, 290-294.

Gibson E. J. (1970). The development of perception as an adaptive process. American Science, 58(1), 98-107.

Goswami, U., \& Bryant, P. B. (1990). Phonological skills and learning to read. London: Erlbaum.

Guttorm, T. K., Leppänen, P. H. T., Poikkeus, A.-M., Eklund, K. M., Lyytinen, P., \& Lyytinen, H. (2005). Brain event-related potentials (ERPs) measured at birth predict later language development in children with and without familial risk for dyslexia. Cortex, 41, 291-303.

Guttorm, T. K., Leppänen, P. H. T., Richardson, U., \& Lyytinen, H. (2001). Eventrelated potentials and consonant differentiation in newborns with familial risk for dyslexia. Journal of Learning Disabilities, 34, 534-544.

Guttorm, T. K., Leppänen, P. H. T., Tolvanen, A., \& Lyytinen, H. (2003). Eventrelated potentials in newborns with and without familial risk for dyslexia: principal component analysis reveals differences between the groups. Journal of Neural Transmission, 110, 1059-1074.

Hoff, E., \& Naigles, L. (2002). How children use input to acquire a lexicon. Child Development, 73, 418-433.

Holopainen, L., Ahonen, T., \& Lyytinen, H. (2001). Predicting delay in reading achievement in a highly transparent language. Journal of Learning Disabilities, 34, 401-413.

Kaplan, E., Goodglass, H., \& Weintraub, S. (1983). The Boston Naming Test (2nd ed.). Philadelphia: Lea \& Febiger.

Karlsson, F. (1999). Finnish. An essential grammar. London: Routledge.

Korhonen, T. (1995). The persistence of rapid naming problems in children with reading disabilities: A nine-year follow-up. Journal of Learning Disabilities, 28, 232-239.

Korkman, M., Kirk, U., \& Kemp, S. (1998). NEPSY: A developmental neuropsychological assessment. San Antonio: Psychological Corporation.

Kuhl, P. K., Williams, K. A., Lacerda, F., Stevens, K. N., \& Lindblom, B. (1992). Linguistic experience alters phonetic perception in infants by 6 months of age. Science, 255, 606-608.

Laakso, M.-L., Poikkeus, A.-M., Eklund, K., \& Lyytinen, P. (2004). Children's interest in early shared reading and it's relation to later language and letter 
knowledge in children with and without genetic risk for dyslexia. First Language, 24, 323-345.

Leinonen, S., Müller, K., Leppänen, P. H. T., Aro, M., Ahonen, T., \& Lyytinen, H. (2001). Heterogeneity in adult dyslexic readers: Relating processing skills to the speed and accuracy of oral text reading. Reading and Writing, 14, 265-296.

Leppänen, P. H. T., Eklund, K. M., \& Lyytinen, H. (1997). Event-related brain potentials to change in rapidly presented acoustic stimuli in newborns. Developmental Neuropsychology, 13(2), 175-204.

Lindeman, J. (2000). Ala-asteen lukutesti: Käyttäjän käsikirja [The Comprehensive School Reading Test]. Turku: Oppimistutkimuksen keskus, Turun yliopisto.

Lo, Y., Mendell, N. R., \& Rubin, D. R. (2001). Testing the number of components in a normal mixture. Biometrika, 88, 767-778.

Locke, J. L., Hodgson, J., Macaruso, P., Roberts, J., Lambrecht-Smith, S., \& Guttentag, C. (1997). The development of developmental dyslexia. In C. Hulme \& M. Snowling (Eds.), Dyslexia: Biology, cognition, and intervention (pp. 73-96). London: Whurr.

Lonigan, C. J., Burgess, S. R., \& Anthony, J. L. (2000). Development of emergent literacy and early reading skills in preschool children: Evidence from a latentvariable longitudinal study. Developmental Psychology, 36, 596-613.

Lundberg, I. (1994). Reading difficulties can be predicted and prevented. A Scandinavian perspective on phonological awareness and reading. In C. Hulme \& M. Snowling (Eds.), Reading development and dyslexia (pp. 180-199). London: Whurr.

Lyytinen, H., Ahonen, T., Eklund, K., Guttorm, T. K., Kulju, P., Laakso, M.-L., Leiwo, M., Leppänen, P. H. T., Lyytinen, P., Poikkeus, A.-M., Richardson, U., Torppa, M., \& Viholainen, H. (2004). Early development of children at familial risk for dyslexia-Follow-up from birth to school age. Dyslexia, 10, 146-178.

Lyytinen, H., Ahonen, T., Eklund, K., Guttorm, T. K., Laakso, M.-L., Leinonen, S., Leppänen, P. H. T., Lyytinen, P., Poikkeus, A.-M., Puolakanaho, A., Richardson, U., \& Viholainen, H (2001). Developmental pathways of children with and without familial risk for dyslexia during the first years of life. Developmental Neuropsychology, 20, 535-554.

Lyytinen, H., Aro, M., Eklund, K., Erskine, J., Guttorm, T. K., Laakso, M.-L., Leppänen, P. H. T., Lyytinen, P., Poikkeus, A.-M., Richardson, U., \& Torppa, M. (2004). The development of children at familial risk for dyslexia: birth to school age. Annals of Dyslexia, 54, 184-220.

Lyytinen, H., Aro, M., Holopainen, L., Leiwo, M., Lyytinen, P., \& Tolvanen, A. (2006). Children's language development and reading acquisition in a highly 
transparent orthography. In R. M. Joshi \& P. G. Aaron (Eds.), Handbook of orthography and literacy (pp. 47-62). Mahwah, NJ: Erlbaum.

Lyytinen, H., Guttorm, T. K., Huttunen, T., Hämäläinen, J., Leppänen, P. H. T., \& Vesterinen, M. (2005). Psychophysiology of developmental dyslexia: A review of findings including studies of children at risk for dyslexia. Journal of Neurolinguistics, 18, 167-195.

Lyytinen, H., Leppänen, P. H. T., Richardson, U., \& Guttorm, T. (2003). Brain functions and speech perception in infants at risk for dyslexia. In V. Csépe (Ed.), Dyslexia: Different brain, different behaviour. Neuropsychology and Cognition Series (pp. 113-152). Dordrecht, Netherlands: Kluwer.

Lyytinen, H., Ronimus, M., Alanko, A., Taanila, M., \& Poikkeus, A.-M. (submitted). Early identification and prevention of dyslexia.

Lyytinen, P. (1999). Varhaisen kommunikaation ja kielen kehityksen arviointimenetelmä (Finnish manual for the MacArthur Communicative Development Inventory, CDI). University of Jyväskylä, Child Research Center and Niilo Mäki Institute. Jyväskylä: Yliopistopaino.

Lyytinen, P., Eklund, K., \& Lyytinen, H. (2005). Language development and literacy skills in late-talking toddlers with and without familial risk for dyslexia. Annals of Dyslexia, 55, 166-192.

Lyytinen, P., \& Lyytinen, H. (2004). Growth and predictive relations of vocabulary and inflectional morphology in children with and without familial risk for dyslexia. Applied Psycholinguistics, 25, 397-411.

Lyytinen, P., Poikkeus, A.-M., Laakso, M.-L., Eklund, K., \& Lyytinen, H. (2001). Language development and symbolic play in children with and without familial risk for dyslexia. Journal of Speech, Language and Hearing Research, 44, 873-885.

Manis, F. R., Seidenberg, M. S., \& Doi, L. M. (1999). See dick RAN: rapid naming and the longitudinal prediction of reading subskills in first and second grades. Scientific Studies of Reading, 3, 129-157.

Marshall, J. C., \& Newcombe, F. (1973). Patterns of paralexia: a psycholinguistic approach. Journal of Psycholinguistic Research, 2, 175-199.

Metsälä, J. L., \& Walley, A. C. (1998). Spoken vocabulary growth and the segmental restructuring of lexical representations: Precursors to phonemic awareness and early reading ability. In J. L. Metsala \& L. C. Ehri (Eds.), Word recognition in beginning literacy (pp. 89-120). New York: Erlbaum.

Muthén, B. (2001). Latent variable mixture modeling. In G. A. Marcoulides \& R. E. Schumacker (Eds.), New developments and techniques in structural equation modeling (pp. 1-33). Mahwah, NJ: Erlbaum.

Muthén, L. K., \& Muthén, B. O. (2004). Mplus User's Guide. Los Angeles.

Nevala, J., \& Lyytinen, H. (2001). Sanaketjutesti [Word Chain Test]. Jyväskylä: Niilo Mäki Instituutti ja Jyväskylän yliopiston Lapsitutkimuskeskus. 
Pennington, B. F. (1991). Diagnosing learning disorders: A neuropsychological framework. New York: Guilford.

Pennington, B. F., \& Lefly, D. L. (2001). Early reading development in children at family risk for dyslexia. Child Development, 72, 816-833.

Poskiparta, E., Niemi, P., Lepola, J., Ahtola, A., \& Laine, P. (2003). Motivationalemotional vulnerability and difficulties in learning to read and spell. British Journal of Educational Psychology, 73, 187-206.

Puolakanaho, A., Poikkeus, A.-M., Ahonen, T., Tolvanen, A., \& Lyytinen, H. (2003). Assessment of three-and-a-half-year-old children's emerging phonological awareness in a computer animation context. Journal of Learning Disabilities, 36, 416-423.

Puolakanaho, A., Poikkeus, A.-M., Ahonen, T., Tolvanen, A., \& Lyytinen, H. (2004). Emerging phonological awareness as a precursor of risk in children with and without familial risk for dyslexia. Annals of Dyslexia, 54, 221-243.

Reynell, J., K., \& Huntley, M. (1987). Reynell Developmental Language Scales Manual (2nd ed.). Windsor, UK: NFER-Nelson.

Richardson, U. (1998). Familial dyslexia and sound duration in the quantity distinctions of Finnish infants and adults. Studia Philologica Jyväskyläensia, 44. Jyväskylä: University Printing House

Scarborough, H. S. (1990). Very early language deficits in dyslexic children. Child Development, 61, 1728-1743.

Scarborough, H. S. (2001). Connecting early language and literacy to later reading (dis)abilities: Evidence, theory, and practice. In S. Neuman \& D. Dickinson (Eds.), Handbook for research in early literacy (pp. 97-110). New York: Guilford.

Seymour, P. H. K., Aro, M., \& Erskine, J. M. (2003). Foundation literacy acquisition in European orthographies. British Journal of Psychology, 94, 143-174.

Shaywitz, B. A., Shaywitz, S. E., Blachman, B. A., Pugh, K. R., Fulbright, R. K., Skudlarski, P., Mencl, W. E., Constable, R. T., Holahan, J. M., Marchione, K. E., Fletcher, J. M., Reid Lyon, G., \& Gore, J. C. (2004). Development of left occipitotemporal systems for skilled reading in children after a phonologically-based intervention. Biological Psychiatry, 55, 926-933.

Snow, C. E., Burns, M. S., \& Griffin, P. (Eds.). (1998). Preventing reading difficulties in young children. Washington, DC: National Academy Press.

Snowling, M. J. (1998). Dyslexia as a phonological deficit: Evidence and implications. Child Psychology and Psychiatry Review, 3(1), 4-11.

Snowling, M. J., Gallagher, A., \& Frith, U. (2003). Family risk of dyslexia is continuous: Individual differences in the precursors of reading skill. Child Development, 74, 358-373.

Stanovich, K. E. (1990). Explaining the differences between the dyslexic and the garden-variety poor reader. The phonological-core variable difference model. Journal of Learning Disabilities, 21, 690-604. 
Taipale, M., Kaminen, N., Nopola-Hemmi, J., Haltia, T., Myllyluoma, B., Lyytinen, H., Müller, K., Kaaranen, M., Lindsberg, P. J., Hannula-Jouppi, K., \& Kere, J. (2003). A candidate gene for developmental dyslexia encodes a nuclear tetratricopeptide repeat domain protein dynamically regulated in brain. Proceedings of the National Academy of Sciences, 100, 11553-11558.

Thaler, V., Ebner, E., Wimmer, H., \& Landerl, K. (2004). Training reading fluency in dysfluent readers with high reading accuracy: Word specific effects but low transfer to untrained words. Annals of Dyslexia, 54(1), 89-113.

Torppa, M., Poikkeus, A.-M., Laakso, M.-L., Leskinen, E., Tolvanen, A., Puolakanaho, A., Leppänen, P. H. T., \& Lyytinen, H. (submitted). Modelling the early paths of phonological awareness and factors supporting its development in children with and without familial risk of dyslexia.

Vellutino, F. V., Fletcher, J. M., Snowling, M. J., \& Scanlon, D. M. (2004). Specific reading disability (dyslexia): what we have learned in the past four decades. Journal of Child Psychology and Psychiatry, 45, 2-40.

Viholainen, H., Ahonen, T., Lyytinen, P., Cantell, M., Tolvanen, A., \& Lyytinen, H. (2006). Early motor development and later language and reading skills in children at risk for familial dyslexia. Developmental Medicine and Child Neurology, 48, 367-373.

Wagner, R. K., Torgesen, J. K., \& Laughon, P. (1993). Development of young readers' phonological processing abilities. Journal of Educational Psychology, 85, 83-103.

Wagner, R. K., Torgesen, J. K., \& Rashotte, C. A. (1994). Development of readingrelated phonological processing abilities: New evidence of bi-directional causality from a latent variable longitudinal study. Developmental Psychology, 30, 73-87.

Wechsler, D. (1989). Wechsler Preschool and Primary Scale of IntelligenceRevised. San Antonio: Psychological Corporation.

Wimmer, H. (1993). Characteristics of developmental dyslexia in a regular writing system. Applied Psycholinguistics, 14, 1-33.

Wimmer, H., Mayringer, H., \& Landerl, K. (1998). Poor reading: A deficit in skillautomatization or phonological deficit? Scientific Studies of Reading, 2, $321-340$.

Wimmer, H., Mayringer, H., \& Landerl, K. (2000). The double-deficit hypothesis and difficulties in learning to read a regular orthography. Journal of Educational Psychology, 92, 668-680.

Wolf, M. (1984) Naming, reading and the dyslexias: A longitudinal overview. Annals of Dyslexia, 34, 87-115.

Wolf, M., \& Bowers, P. G. (1999).The double-deficit hypothesis for the developmental dyslexias. Journal of Educational Psychology, 91, 415-438.

Wolf, M., Bowers, P. G., \& Biddle, K. (2000). Naming-speed processes, timing, and reading: A conceptual review. Journal of Learning Disabilities, 33, 387-407. 